\title{
A Point Prevalence Study of Urinary Catheter Use Among Teaching Hospitals With and Without Reduction Programs
}

\author{
Christine Soong, MD, MSc ${ }^{1,2 *}$, Jerome A. Leis, MD, MSc ${ }^{2,3}$, Karen Okrainec, MD, MSc ${ }^{4}$, \\ Emily G. McDonald, MD, MSc ${ }^{5,6}$, Todd C. Lee, MD, MPH ${ }^{5,6}$
}

\begin{abstract}
${ }^{1}$ Division of General Internal Medicine, Mount Sinai Hospital, Toronto, Canada; 2Institute of Health Policy, Management and Evaluation, University of Toronto, Toronto, Canada; 'Division of Infectious Diseases and General Internal Medicine, Sunnybrook Health Sciences Centre, Toronto, Canada; ${ }^{4}$ Division of General Internal Medicine, University Health Network, Toronto, Canada; ${ }^{5}$ Division of General Internal Medicine, McGill University Health Centre, Montreal, Canada; ${ }^{6}$ Clinical Practice Assessment Unit, McGill University Health Centre, Montreal, Canada.
\end{abstract}

Urinary catheter use can be associated with urinary tract infections, delirium, trauma, and immobility. ${ }^{1}$ Evidencebased strategies to reduce inappropriate use are available ${ }^{2}$; however, their application across centers is variable. ${ }^{3}$ We aimed to characterize the prevalence and indication for catheters among Canadian teaching hospitals with and without catheter reduction programs.

\section{METHODS}

Twelve of 17 postgraduate internal medicine training program directors agreed to participate, and 9 Canadian teaching hospitals enrolled in this prevalence study of urinary catheter use among medical inpatients. Data collection used a standardized form and took place over 5 consecutive weekdays during August 2015. Each site anonymously collected the total number of catheters, total number of inpatient-days, and indications for use from either the bedside nurse or physician. Appropriate clinical indications were based on the 2009 guidelines from the Healthcare Infection Control Practice Advisory Committee. ${ }^{4}$ Potentially inappropriate indications included urine output measurement in non-critically ill patients, and "other" or "unknown" indications. ${ }^{4,5} \mathrm{~A}$ catheter reduction program was defined as the presence of a structured system to monitor and reduce use via: nurse-directed catheter removal, audit-feedback of use to providers, physician reminders, and/or automatic stop orders.

The primary outcome was the number of catheter days per 100 inpatient-days. We used generalized estimating equations to adjust the $95 \%$ confidence interval $(\mathrm{CI})$ and $P$ value to account for hospital-level clustering of the responses. The $P$ values are from a 2-tailed Wald test against the true $\log$ scale parameter being equal to zero. The analysis was performed using $\mathrm{R}$ version 3.0.2

*Address for correspondence and reprint requests: Christine Soong, MD, Mount Sinai Hospital, 428-600 University Avenue, Toronto, Ontario, Canada M5G 1X5; Telephone: 416-586-4800; Fax: 647-776-3148; E-mail: christine.soong@utoronto.ca

Additional Supporting Information may be found in the online version of this article.

Received: March 21, 2016; Revised: May 18, 2016; Accepted: May 22, 2016

2016 Society of Hospital Medicine DOI 10.1002/jhm.2628

Published online in Wiley Online Library (Wileyonlinelibrary.com). using the geepack package (Free Software Foundation, Boston, MA).

The McGill University Health Centre Research Ethics Board approved this study with concomitant authorization at participating sites.

\section{RESULTS}

The characteristics of participating hospitals are displayed in Table 1. Those with active catheter reduction programs reported established systems for monitoring catheter placement, duration, and catheter-associated urinary tract infections. More than half of the hospitals lacked a catheter reduction program. Overall, catheters were present on $13.6 \%$ of patient-days (range, $2.3 \%$ $32.4 \%$ ). Centers without reduction programs reported higher rates of catheter use both overall and for potentially inappropriate indications. After adjustment for clustering, those with a formal intervention had 8.8 fewer catheter days per 100 patient-days as compared to those without (9.8 [95\% CI: $6.0-15.6]$ vs 18.6 [95\% CI: 13.0-26.1], $P=0.03)$. This meant that the odds of a urinary catheter being present were 2 times $(95 \%$ CI: 1.0-3.4) greater in hospitals without reduction programs. Differences in appropriate catheter use did not reach statistical significance.

\section{DISCUSSION}

Despite the availability of consensus guidelines for appropriate use and the efforts of movements like Choosing Wisely, many Canadian teaching hospitals have not yet established a urinary catheter reduction program for medical inpatients. Our findings are similar to 2 nonCanadian studies, which demonstrated that fewer than half of hospitals had implemented control measures. ${ }^{4,6}$ In contrast to those other studies, our study demonstrated that hospitals that employed control measures had reduced rates of catheter use suggesting that systematic, structured efforts are necessary to improve practice. ${ }^{7,8}$

Ours is the first nation-wide study in Canada to report urinary catheter rates and the effect of associated reduction programs. Data from the National Healthcare Safety Network suggest our Canadian estimates of urinary catheter rates in medical inpatients are similar to those of the United States (13.6 vs 14.8 catheter days per 100 inpatient-days, respectively, for general medical inpatients). ${ }^{9,10}$ 
TABLE 1. Urinary Catheter Prevalence and Indication in Nine Urban Canadian Hospitals

\begin{tabular}{|c|c|c|c|c|c|c|c|c|c|c|}
\hline \multirow[b]{2}{*}{ Characteristic } & \multicolumn{9}{|c|}{ Hospital } & \multirow[b]{2}{*}{ Overall, $n(\%)^{\prime}$} \\
\hline & A & B & C & D & E & $\mathrm{F}$ & G & $\mathrm{H}$ & 1 & \\
\hline Total beds, $n$ & 442 & 533 & 824 & 505 & 272 & 925 & 650 & 777 & 446 & 5,374 \\
\hline Has system in place to monitor urinary catheter placement & Yes & Yes & Yes & Yes & № & No & № & № & № & N/A \\
\hline $\begin{array}{l}\text { Has system in place to monitor duration and/or } \\
\text { discontinuation of urinary catheters }\end{array}$ & Yes & Yes & Yes & № & No & No & № & No & No & N/A \\
\hline $\begin{array}{l}\text { Has a system in place for monitoring catheter } \\
\text { associated urinary tract infection rates }\end{array}$ & Yes & Yes & Yes & Yes & Yes & Yes & Yes & No & No & N/A \\
\hline Presence of a UC reduction program & Active $\dagger$ & Active $\$$ & Active†t§ & Activeł & № & No & No & № & No & $N / A$ \\
\hline Duration of UC reduction program, y & 1 & 2 & 1 & 1 & N/A & $N / A$ & $N / A$ & N/A & N/A & $N / A$ \\
\hline Total patient-days & 425 & 455 & 527 & 405 & 87 & 311 & 285 & 394 & 253 & 3142 \\
\hline Total UC days & 27 & 32 & 42 & 77 & 2 & 36 & 48 & 80 & 82 & 426 \\
\hline UC rate per 100 patient-days & 6.4 & 7.0 & 8.0 & 19.0 & 2.3 & 11.6 & 16.8 & 20.3 & 32.4 & 13.6 \\
\hline Reported historical UC rate per 100 patient-days $\|$ & 12.0 & 16.5 & 18.8 & $N / A$ & N/A & $N / A$ & $N / A$ & N/A & $N / A$ & N/A \\
\hline Potentially appropriate indications, $n(\%) \uparrow$ & $19(70)$ & $25(78)$ & $30(71)$ & $36(47)$ & 0 & $33(92)$ & $27(56)$ & $32(40)$ & $59(72)$ & $261(61)$ \\
\hline Obstruction & $5(19)$ & $11(34)$ & $19(45)$ & $7(9)$ & 0 & $1(3)$ & $10(21)$ & $20(25)$ & $2(2)$ & $75(17.6)$ \\
\hline Retention & $10(37)$ & $9(28)$ & $7(17)$ & $21(27)$ & 0 & $22(61)$ & $9(19)$ & $11(14)$ & $23(28)$ & $112(26.3)$ \\
\hline Palliative & $4(15)$ & 0 & $4(10)$ & $8(10)$ & 0 & $10(28)$ & $5(10)$ & $1(1)$ & $16(20)$ & $93(21.8)$ \\
\hline Sacral ulcer & 0 & $5(16)$ & 0 & 0 & 0 & 0 & $3(6)$ & 0 & $18(22)$ & $26(6.1)$ \\
\hline Potentially inappropriate indications, $n(\%) \uparrow$ & $8(30)$ & $8(25)$ & $12(28)$ & $50(65)$ & $2(100)$ & $3(8)$ & $21(44)$ & $70(88)$ & $16(20)$ & $190(45)$ \\
\hline Urine output & $2(7)$ & 0 & $1(2)$ & $22(14)$ & $2(100)$ & $3(8)$ & $11(23)$ & $50(35)$ & $8(10)$ & $96(22.5)$ \\
\hline Other & $6(22)$ & $8(25)$ & $10(24)$ & $26(32)$ & 0 & 0 & $5(10)$ & $13(16)$ & 0 & $68(16.0)$ \\
\hline Unknown & 0 & 0 & $1(2)$ & $2(3)$ & 0 & 0 & $5(10)$ & $7(9)$ & $8(10)$ & $23(5.3)$ \\
\hline
\end{tabular}

NOTE: Catheter inserted for the following indications: obstruction = bladder outlet obstruction; retention = acute urinary retention; palliative = indications to achieve comfort for patients at the end of life; sacral ulcer = to allow healing of stage 3 or 4 sacral ulcers in incontinent patients; urine output = to monitor strict urinary output ; other = indications exclusive of the specified indications; unknown = the provider is unaware of indications for insertion. Abbreviations: N/A, not applicable; UC, urinary catheter. *Percentages are row percentages. †Nurse directive. †̦Physician reminder. §Audit feedback. \|Reported historical rates by hospital (A: 2013 point prevalence rate; B: 2013 mean; C: 2014 point prevalence rate). ๆPercentages are column percentages with total UC days as denominator and sum total may exceed 100\% if patients had more than 1 indication specified.

Several limitations of this study warrant discussion. First, we sampled only academic institutions at 1 time point, which may not represent annualized rates or rates in community hospitals. However, our findings are similar to those reported in previous studies. ${ }^{10}$ Second, our method of consecutive daily audits may have caused individuals to change their behavior knowing that they were being observed, resulting in lower catheter utilization than would have been otherwise present and biasing our estimates of catheter overuse downward. Third, we collected point prevalence data, limiting our ability to make inferences on causality. The key factor(s) contributing to observed differences between hospitals remains unknown. However, prepost intervention data available for 3 hospitals suggest that improvements followed active catheter reduction efforts. ${ }^{7,8}$ Fourth, we were unable to obtain outcome data such as catheter-associated urinary tract infection, delirium, or fall rates. However, catheter reduction is widely recognized as an important first step to reducing preventable harm for hospital patients.

We suggest that the broader uptake of structured models of care that promote early discontinuation of urinary catheters on medical wards is needed to improve their appropriateness. Fortunately, it appears as though a variety of models are effective. Therefore, when it comes to adopting Choosing Wisely's "less is more" philosophy toward urinary catheter utilization, we suggest that less time be allowed to pass before more proven and structured interventions are universally implemented.

\section{Acknowledgements}

The authors are indebted to John Matelski, MSc, for statistical analyses.

Disclosures: The Canadian Society of Internal Medicine and its Choosing Wisely Canada Subcommittee supported this work. The authors report no conflicts of interest.

\section{References}

1. Hooton TM, Bradley SF, Cardenas DD, et al. Diagnosis, prevention, and treatment of catheter-associated urinary tract infection in adults: 2009 international clinical practice guidelines from the Infectious Diseases Society of America. Clin Infect Dis. 2010;50(5): 625-663.

2. Lo E, Nicolle LE, Coffin SE, et al. Strategies to prevent catheter-associated urinary tract infections in acute care hospitals: 2014 update. Infect Control Hosp Epidemiol. 2014;35(5):464-479.

3. Saint S, Greene MT, Kowalski CP, et al. Preventing catheterassociated urinary tract infection in the United States: a national comparative study. JAMA Intern Med. 2013;173(10):874-879.

4. Gould CV, Umscheid CA, Agarwal RK, et al, Healthcare Infection Control Practices Advisory Committee. Guideline for prevention of catheter-associated urinary tract infections 2009. Infect Control Hosp Epidemiol. 2010;31(4):319-326.

5. Saint S, Wiese J, Amory JK, et al. Are physicians aware of which of their patients have indwelling urinary catheters? Am J Med. 2000; $109(6): 476-480$.

6. Conway LJ, Pogorzelska M, Larson E, et al. Adoption of policies to prevent catheter-associated urinary tract infections in United States intensive care units. Am J Infect Control. 2012;40(8): 705-710.

7. Leis JA, Corpus C, Rahmani A, et al. Medical directive for urinary catheter removal by nurses on general medical wards. JAMA Intern Med. 2016;176(1):113-115.

8. Schwartz BC, Frenette C, Lee TC, et al. Novel low-resource intervention reduces urinary catheter use and associated urinary tract infections: role of outcome measure bias? Am I Infect Control. 2015;43(4):348-353.

9. Dudeck MA, Edwards JR, Allen-Bridson K, et al. National Healthcare Safety Network report, data summary for 2013, Device-associated Module. Am I Infect Control. 2015;43(3):206-221.

10. Greene MT, Fakih MG, Fowler KE, et al. Regional variation in urinary catheter use and catheter-associated urinary tract infection: results from a national collaborative. Infect Control Hosp Epidemiol. 2014;35(suppl 3):S99-S106. 